\title{
Minimal invasive approach for beyond total mesorectal excision/extended resections in rectal cancer
}

\author{
Naveena A. N. Kumar, Praveen Kammar, Avanish Saklani \\ Department of Colorectal Surgical Oncology and Robotic Surgery, Tata Memorial Centre, Mumbai, Maharashtra 400012, India. \\ Correspondence to: Dr. Avanish Saklani, Department of Colorectal Surgical Oncology and Robotic Surgery, Tata Memorial \\ Centre, Dr Ernest Borges Marg, Parel, Mumbai, Maharashtra 400012, India. E-mail: asaklani@hotmail.com
}

How to cite this article: Kumar NAN, Kammar P, Saklani A. Minimal invasive approach for beyond total mesorectal excision/ extended resections in rectal cancer. Mini-invasive Surg 2018;2:19. http://dx.doi.org/10.20517/2574-1225.2018.26

Received: 15 May 2018 First Decision: 2 Jul 2018 Revised: 7 Jul 2018 Accepted: 9 Jul 2018 Published: 23 Jul 2018

Science Editor: Gordon N. Buchanan Copy Editor: Jun-Yao Li Production Editor: Cai-Hong Wang

\begin{abstract}
Minimal invasive surgery (MIS) is an accepted modality of treatment for rectal cancer. The indications for MIS have gradually been extended to locally advanced and locally recurrent rectal cancer as a result of technological advances in instrumentation, advances in surgical techniques, increased surgeon experience, and high volume center. However, safety and feasibility of laparoscopic surgery and robotic surgery in beyond total mesorectal excision (b-TME) and extended TME (e-TME) are not well established. This review summarizes the current evidence for MIS approach for b-TME/extended resections in rectal cancer. A systematic search was carried out in PubMed. Studies available in English related to MIS approach in b-TME/e-TME in rectal cancers were identified and evaluated. This review concludes MIS is feasible with good perioperative outcomes in b-TME/e-TME in carefully selected patients. Laparoscopic surgery has considerable learning curve and should be performed by experienced surgical teams. Robotic surgery is feasible and beneficial in complex resection in pelvis. However, evidence for long-term oncological outcomes of MIS in b-TME/e-TME is low and needs to be studied further by randomized controlled trial once enough numbers are possible in institutes with high volume rate.
\end{abstract}

Keywords: Minimal invasive surgery, laparoscopic surgery, robotic surgery, beyond total mesorectal excision, extended resection, locally advanced rectal cancer, pelvic exenteration, lateral pelvic lymph node dissection

\section{INTRODUCTION}

Total mesorectal excision (TME) is a standard of care for primary rectal cancer located within mesorectal fascia. In locally advanced and locally recurrent tumors extending beyond mesorectal fascia, removal of

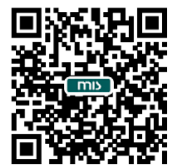


total mesorectum along with en bloc resection of involved pelvic structures often required to achieve Ro status ${ }^{[1]}$. Magnetic resonance imaging (MRI) of pelvis is accurate in staging of locally advanced and locally recurrent rectal cancer ${ }^{[2,3]}$. On the basis of the involvement of fascial boundaries and the anatomic planes of dissection between intra-pelvic organs in the MRI, pelvis was divided into seven compartments, namely the central, peritoneal reflection, anterior above and below the peritoneal reflection, posterior, lateral, and inferior compartments ${ }^{[4]}$. The locally advanced and locally recurrent rectal cancers were classified depending on the MRI findings of tumor invasion within seven intra-pelvic compartments ${ }^{[2]}$.

The extended-TME (e-TME) is defined as partial resection of adjacent organ(s) of the rectum such as posterior wall of the prostate or the vagina, the uterus, the seminal vesicles, the hypogastric plexuses, the ureter, and bladder en bloc with the TME with curative intent, to achieve a Ro resection ${ }^{[5,6]}$. The beyond-TME (b-TME) includes posterior pelvic exenteration, total pelvic exenteration, extralevator abdomino-perineal resection for inferior compartment involvement, and sacral resection for posterior compartment involvement ${ }^{[5,7]}$. Lateral pelvic lymph node dissection is considered for subgroup of patients with clinically suspected lateral pelvic lymph node metastasis, even after neo-adjuvant chemo-radiotherapy ${ }^{[8,9]}$.

Only few specialized multidisciplinary units across the world perform these aggressive resections as the morbidity and mortality associated with these surgeries is very high ${ }^{[10]}$. Refinement and standardization of these techniques forge the way forward in improving outcomes. Multidisciplinary team approach, advances in surgical technique, perioperative care, interventional radiology, and better patient selection have contributed to the decrease in complication rates, making it feasible for an increasing number of surgical units to adopt these aggressive surgical techniques.

Minimal invasive surgery (MIS) is an accepted modality of treatment for rectal cancer. Laparoscopic resection improves perioperative outcomes, including decrease in intraoperative blood loss, postoperative pain, ileus, and duration of hospital stay. Randomized trials such as the CLASICC (Conventional vs. LaparoscopicAssisted Surgery in Colorectal) trial, COREAN (Comparison of Open vs. Laparoscopic Surgery for Mid or Low Rectal Cancer after Neoadjuvant Chemoradiotherapy) trial, and COLOR II (Colorectal Cancer Laparoscopic or Open Resection II) trials have confirmed the feasibility and oncological safety of laparoscopic surgery in $\mathrm{TME}^{[11-13]}$. Despite the advantages, laparoscopic surgery has some limitations, such as unstable, two-dimensional view, limitations in the freedom degrees of the surgical instruments, the amplification of the physiological tremor and the "fulcrum" effect, and poor ergonomics ${ }^{[1,15]}$. The robotic surgery overcomes these disadvantages and improves the ergonomics of the surgeon ${ }^{[16]}$. The robotic surgery helps reduce hospital stay and conversion rates and similar oncological outcomes in $\mathrm{TME}^{[17-19]}$. But recently, ROLARR (RObotic vs. LAparoscopic Resection for Rectal Cancer) trial revealed that robotic-assisted laparoscopic surgery do not confer an advantage over laparoscopic surgery in rectal cancer resection for $\mathrm{TME}^{[20]}$. However this trial did not address the e-TME/b-TME.

The aforementioned randomized trials have excluded cT4 lesions. Bretagnol et al. ${ }^{[21]}$ assessed feasibility and oncological outcomes of laparoscopic surgery for cT4 colorectal cancer and suggested that locally advanced rectal cancer cannot be considered as absolute contraindication. A multicenter propensity score-matched analysis of laparoscopic surgery $v s$. open surgery for T4 rectal cancer by de'Angelis et al. ${ }^{[2]}$ suggested that laparoscopic surgery can achieve good pathological and oncological outcomes similar to open surgery with faster recovery and shorter hospital stay, despite the risk of conversion. The indications for MIS have gradually been extended to locally advanced and locally recurrent rectal cancer as a result of technological advances in instrumentation, advances in surgical techniques, increased surgeon experience, and high volume center, which suggested laparoscopic surgery is feasible with good perioperative outcomes ${ }^{[23-25]}$. Kim et al ${ }^{[26]}$ reported that laparoscopic multivisceral resection seems to be a feasible and effective treatment option for colorectal cancer for carefully selected patients without any adverse long-term oncological outcomes. However, safety 
and feasibility of laparoscopic and robotic surgery in b-TME and e-TME are not well established, and there are very few studies in the world literature. This review summarizes current evidence for MIS approach for b-TME/extended resections in rectal cancer.

\section{METHODS}

A systematic search was carried out in PubMed. Studies available in English related to MIS approach in b-TME/e-TME in rectal cancers were identified and evaluated. Keywords used were "MIS, laparoscopic surgery, robotic surgery, b-TME, e-TME, locally advanced rectal cancer, pelvic exenteration, extended resection, lateral pelvic lymph node dissection, abdominosacral resection". The perioperative outcomes such as duration of surgery, blood loss, conversion rate, overall morbidity, hospital stay, Ro status, and long-term outcomes such as local recurrence rate, disease-free survival, and overall survival (OS) were studied.

\section{PELVIC EXENTERATION}

Local control and long-term survival in locally advanced and locally recurrent rectal cancer mainly depend on Ro resection ${ }^{[1]}$. Complete en bloc resection of the tumor along with adjacent structures depending on the location and depth of invasion is important to achieve Ro status ${ }^{[27]}$. Pelvic exenteration by open approach is a standard of care for locally advanced and locally recurrent rectal cancer. MIS for pelvic exenteration is not well established. Only few studies have been described and have confirmed the feasibility and short-term outcomes. Whenever feasible and appropriate, MIS can be performed.

The locally advanced and locally recurrent rectal cancers with invasion limited to the anterior pelvic organ are good candidates for laparoscopic pelvic exenteration as a free circumferential margin can be achieved easily ${ }^{[28]}$. The b-TME Collaborative has generated a consensus guideline suggesting certain contraindications for these resections $s^{[7]}$, which holds true for MIS also. Absolute contraindications are poor performance status/medically unfit patients, bilateral sciatic nerve involvement, and circumferential bone involvement. Relative contraindications include extension of tumor through the sciatic notch, encasement of external iliac vessels - requiring en bloc resection and/or reconstruction of external iliac vessels, high sacral involvement (above $\mathrm{S}_{2} / \mathrm{S} 3$ ), and predicted R2 resection. Patients who underwent multiple laparotomies and predicted to have severe small bowel adhesion are precluded from having $\mathrm{MIS}^{[29]}$.

Initial experience in laparoscopic pelvic exenteration was reported in few case reports and video vignette ${ }^{[28,30]}$. Akiyoshi et al. ${ }^{[31]}$ demonstrated an laparoscopic pelvic exenteration for locally recurrent rectal cancer and suggested that laparoscopic pelvic exenteration was a technically challenging procedure that requires a long operative time with benefits of a very clear view of the operative field, allowing precise dissection, less blood loss, and a smaller abdominal wound.

One of the initial experiences of laparoscopic pelvic exenteration come from Uehara et al. ${ }^{[29]}$. They discussed the technical points of laparoscopic pelvic exenteration and compared the short-term results of laparoscopic pelvic exenteration with those of conventional open pelvic exenteration. The surgeon performed posterior and lateral pelvic wall dissection in the initial part of surgery and anterior dissection in the last phase to avoid suspension of urinary bladder. Dissection along internal iliac vessels and identification and transection of small branches are important to avoid intraoperative bleeding ${ }^{[29]}$. The dorsal vein complex was clipped and divided using bipolar soft-coagulation of a VIO system. Investigators observed that laparoscopic-guided perineal approach avoided much blood loss by helping proper dissection. Intraoperative blood loss was significantly lower in laparoscopic pelvic exenteration group (830 vs. $2769 \mathrm{~mL}$, $P=0.003$ ), and operative time and rate of Ro resection were similar in both groups. The authors concluded that laparoscopic pelvic exenteration performed by an experienced pelvic surgeon was safe and efficient in carefully selected patients. 


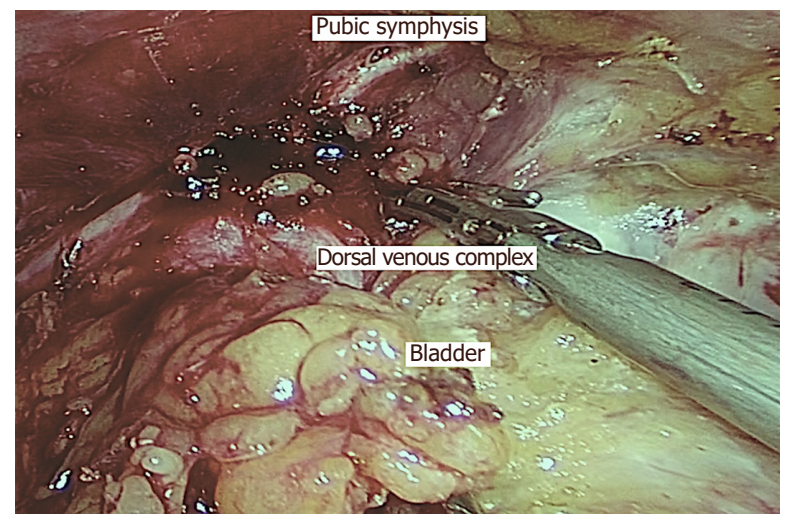

Figure 1. Laparoscopic pelvic exenteration with division of dorsal vein complex using Ligaclip and Harmonic Ace (Ethicon, India)

Ogura et al. ${ }^{[32]}$ compared perioperative outcomes of laparoscopic pelvic exenteration $(n=13)$ with open approach $(n=18)$, and results were similar to those of Uehara et al. ${ }^{[29]}$. The estimated blood loss $(930 \mathrm{vs}$. $3003 \mathrm{~mL} ; P=0.001)$ and total volume of blood transfusion (0 vs. $1990 \mathrm{~mL} ; P=0.002$ ) were significantly lower in patients undergoing laparoscopic pelvic exenteration compared with those undergoing open pelvic exenteration. The operative time, complications rate, and postoperative hospital stay were similar in both the groups. According to the authors reduced blood loss in laparoscopic pelvic exenteration group was due to the high-definition, illuminated, and magnified view to detect smaller vessels and control the bleeding, and the high pneumoperitoneal pressure to reduce venous oozing. The dorsal vein complex was transected after intracorporeal suturing in most of the patients and when patient required sacral resection or perineal reconstruction, dorsal vein complex was divided under direct vision. There was no conversion to open and all achieved Ro resection. Investigator emphasizes on careful selection of patients, as those with tumors spreading only to the prostate and requiring total pelvic exenteration are better candidates than those with urinary bladder also being invaded and requiring anterior pelvic exenteration.

Our institute is a high volume referral center for colorectal cancer ${ }^{[33]}$ and we do perform e-TME, b-TME, and multivisceral resection for locally advanced and locally recurrent rectal cancer ${ }^{[34-36]}$. We standardized our technique of laparoscopic pelvic exenteration ${ }^{[37,38]}$. We use standard five-port technique followed by medialto-lateral retroperitoneal dissection, inferior mesenteric artery division, dissection of retrorectal space up to origin of levator ani, pararectal space dissection after medializing ureters, dissection of paravesical space to the level of the endopelvic fascia, dissection of Retzius space, division of dorsal vein complex, urethral transection, division of ureters, sigmoid transection, perineal dissection, and Bricker's ileal conduit through small infraumbilical incision. In patients who already have transverse stoma, previous stoma was retained and ureterosigmoid anastomosis was performed after stapling the sigmoid colon distal to the transverse stoma. We emphasize on transection of ureters at the end of abdominal part surgery for monitoring urine output and avoiding urine leak. We divide dorsal vein complex at the last stage of pelvic dissection using Ligaclip and Harmonic Ace (Ethicon, India) [Figure 1]. In case of bleeding, we would increase abdominal gas pressure, pack with tape gauze, and suture during perineal part of surgery. In our study, blood loss was $1000 \mathrm{~mL}$ (range 300-2000 mL), mean duration of surgery was $9.13 \mathrm{~h}$ (range 7-13 h), and mean postoperative stay was 14.6 days (range 9-25 days) ${ }^{[38]}$. When compared to other studies, we have demonstrated good perioperative outcomes [Table 1].

Hayashi et al..$^{[39]}$ reported that laparoscopic pelvic exenteration using transanal minimal invasive surgery has certain advantages. They claimed that good visual field in the pelvis can be maintained even after entry into abdominal cavity as pneumoperirectum is sustained by the pneumoperitoneum. The small perineal wound and less bleeding reduce the perineal surgical site infection. Uematsu et al. ${ }^{[40]}$ also confirmed the advantages 
Table 1. Case series of laparoscopic pelvic exenteration and outcomes

\begin{tabular}{|c|c|c|c|c|c|c|c|c|c|}
\hline Study & Year & $\begin{array}{c}\text { Number of } \\
\text { patients }(n)\end{array}$ & $\begin{array}{c}\text { Median } \\
\text { operative time, } \\
\text { min (range) }\end{array}$ & $\begin{array}{l}\text { Median } \\
\text { blood loss, } \\
\text { mL (range) }\end{array}$ & $\begin{array}{l}\text { Conversion } \\
\text { to open (\%) }\end{array}$ & $\begin{array}{c}\text { Overall } \\
\text { complications } \\
(\%)\end{array}$ & $\begin{array}{l}\text { Hospital } \\
\text { stay } \\
\text { (days) }\end{array}$ & $\begin{array}{c}\text { R0 status } \\
\text { (\%) }\end{array}$ & $\begin{array}{l}\text { Follow-up } \\
\text { (months) }\end{array}$ \\
\hline $\begin{array}{l}\text { Uehara } \\
\text { et al.[.29] }\end{array}$ & 2015 & $\begin{array}{l}6 / 48 \\
\text { (LPE/OPE) }\end{array}$ & $\begin{array}{l}935 \\
(716-1219)\end{array}$ & $\begin{array}{l}830 \\
(283-5225)\end{array}$ & 16.7 & 66.7 & $\begin{array}{l}27 \\
(23-53)\end{array}$ & 77.8 & NR \\
\hline $\begin{array}{l}\text { Ogura } \\
\text { et al. } .^{322]}\end{array}$ & 2016 & $\begin{array}{l}13 / 18 \\
\text { (LPE/OPE) }\end{array}$ & 829 & 930 & 0 & 61.5 & 29 & 100 & NR \\
\hline $\begin{array}{l}\text { Pokharkar } \\
\text { et } a^{\left[{ }^{[38]}\right.}\end{array}$ & 2018 & 10 (LPE) & 547 & $\begin{array}{l}1000 \\
(300-2000)\end{array}$ & 0 & 20 & $\begin{array}{l}14.6 \\
(9-25)\end{array}$ & 100 & NR \\
\hline
\end{tabular}

LPE: laparoscopic pelvic exenteration; OPE: open pelvic exenteration; NR: not reported

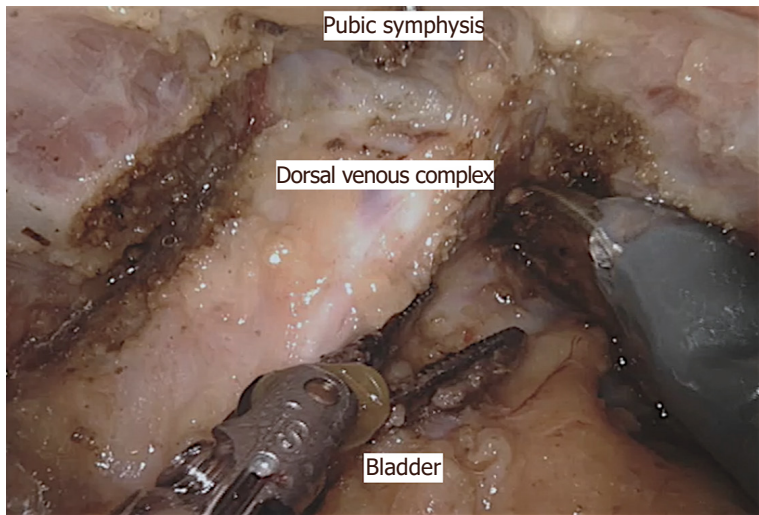

Figure 2. Robotic pelvic exenteration with division of dorsal vein complex

of transanal minimal invasive surgery during perineal part of laparoscopic pelvic exenteration. Investigator suggested that the division of dorsal vein complex is feasible and safe because of broader working area. Injury and bleeding from visceral pelvic fascia can be prevented by dividing the urethra at the junction with prostate and dissecting levator ani along the attachment of internal obturator muscle.

There are a few case series and reports on robotic pelvic exenteration for gynecological, urological, and locally advanced rectal cancer ${ }^{[41-43]}$. One of the first reports of robotic pelvic exenteration for locally advanced rectal cancer come from Shin et al. ${ }^{[4]}$. They described three cases including two extended resections with en bloc prostatectomy and intracorporeal vesicourethral anastomosis, and one total pelvic exenteration with intracorporeal ileal conduit. Winters et al. ${ }^{[45]}$ compared robotic pelvic exenteration with laparoscopic rectus flap and open pelvic exenteration, and reported similar operative times with reduced blood loss, less narcotic usage, shorter intensive care unit stays, and shorter hospital stays. The surgical steps of robotic pelvic exenteration are similar to those of laparoscopic pelvic exenteration ${ }^{[46]}$ [Figures 2, 3 and 4]. Long-term oncological outcomes need to be studied further to implement robotic pelvic exenteration as a standard procedure.

\section{LATERAL PELVIC LYMPH NODE DISSECTION}

The incidence of lateral pelvic lymph node metastasis in locally advanced mid- and low-rectal cancer ranges from $10 \%$ to $25 \%{ }^{[47,48]}$. In Japan, lateral pelvic lymph node involvement is considered as loco-regional disease, and in West, it is regarded as systemic disease ${ }^{[49-51]}$. Thus, present strategies for the management of lateral pelvic lymph node are TME with neo-adjuvant chemo-radiotherapy and/or lateral pelvic lymph node dissection ${ }^{[4752-54]}$. The recent study suggested that patients with lateral pelvic lymph nodes responsive to neoadjuvant chemo-radiotherapy may not benefit from lateral pelvic lymph node dissection and subgroup with persistent lateral pelvic lymph node following neo-adjuvant chemo-radiotherapy may benefit from lateral pelvic lymph node dissection ${ }^{[8]}$. In our institute, we perform lateral pelvic lymph node dissection in selective 


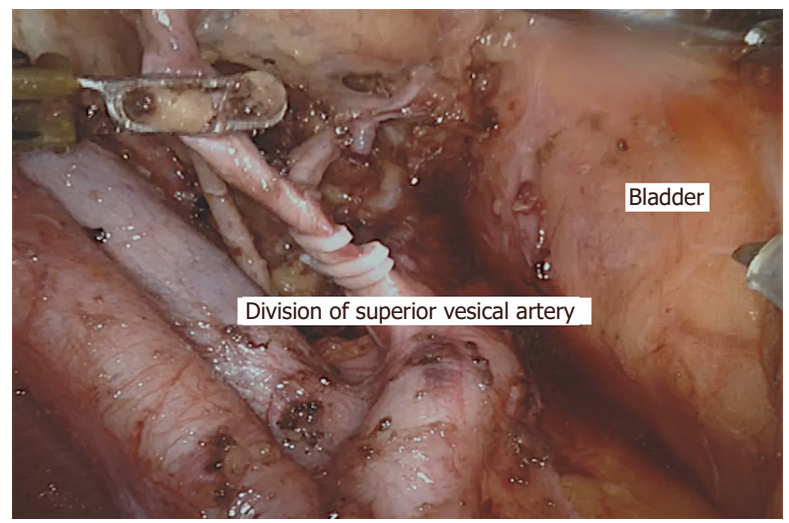

Figure 3. Robotic pelvic exenteration with lateral pelvic lymph node dissection showing division of vesicle artery

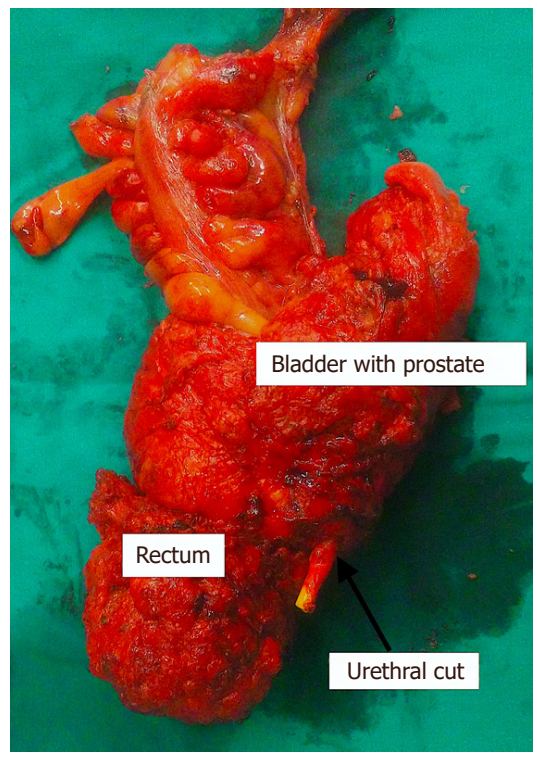

Figure 4. Specimen of total pelvic exenteration

patients with persistent lateral pelvic lymph node dissection after neo-adjuvant chemo-radiotherapy ${ }^{[34,35,55,56]}$. The template of lateral pelvic lymph node dissection in rectal cancer differs from that of genitourinary tract malignancy as it extends inferior to the plane of the obturator nerve up to pelvic floor ${ }^{[57]}$ [Figure 5].

In extending the scope of MIS and its advantages over open approach, high volume centers initiated laparoscopic/robotic lateral pelvic lymph node dissection. One of the initial experiences by Liang ${ }^{[58]}$ suggested that laparoscopic pelvic lymph node dissection is a technically demanding procedure and should be performed by highly experienced laparoscopic surgeons on carefully selected patients. Park et al. ${ }^{[59]}$ reported the technical feasibility, safety, and oncological outcomes of laparoscopic lateral pelvic lymph node dissection following TME with mean number of lateral lymph nodes harvested to be 9.1 (range 3-19). Liu et al. ${ }^{[60]}$ suggested that the laparoscopic radical correction combined with extensive lymphadenectomy and pelvic autonomic nerve preservation is feasible and safe.

Akiyoshi ${ }^{[6]]}$ reviewed the published series involving at least 10 patients with locally advanced low rectal cancer who underwent laparoscopic/robotic lateral pelvic lymph node dissection from 2011 to 2015 and opined that MIS is technically safe and feasible procedure with good perioperative outcomes when performed by 


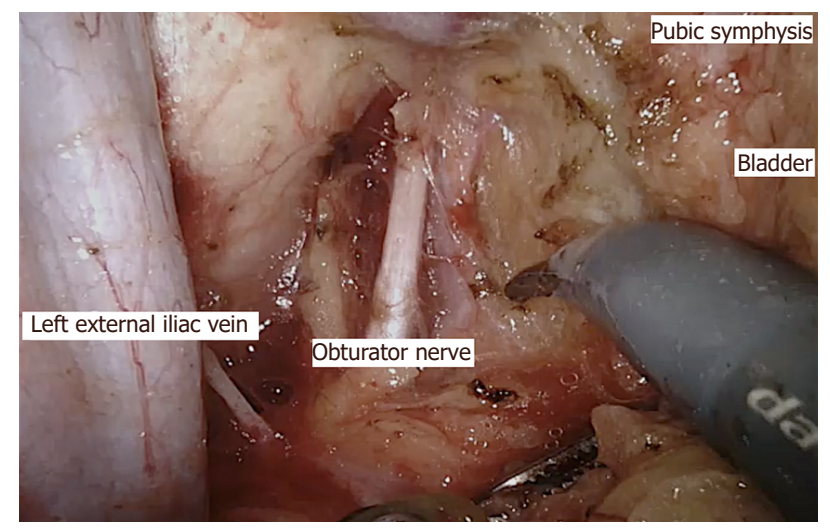

Figure 5. Robotic lateral pelvic lymph node dissection with dissection inferior to obturator nerve

experienced laparoscopic surgeons specializing in pelvic surgery. The author emphasized that lateral pelvic lymph node metastasis more commonly occurs around the distal internal iliac vessels located very deep in the pelvic space ${ }^{[4]}$. With magnified and illuminated vision of MIS and surgeons with good knowledge of lateral pelvic anatomy and sufficient experience in MIS TME procedure, lateral pelvic lymph node dissection can be performed meticulously with less blood loss ${ }^{[6]]}$.

Nagayoshi et al. ${ }^{[62]}$ evaluated the feasibility and oncological safety of laparoscopic lateral pelvic lymph node dissection compared with the conventional open approach. The mean operative time was longer in the laparoscopic group than in the open group (641.0 vs. $312.0 \mathrm{~min}, P<0.001)$. The laparoscopic group had less blood loss (252.0 vs. $815.0 \mathrm{~mL}, P<0.001)$ and a shorter hospital stay $(22.9$ vs. 29.1 days, $P=0.04)$ than the open group. The morbidity rate and OS (3-year OS: $94.7 \%$ vs. $82.9 \%, P=0.25$ ) did not differ between the two groups. The mean number of harvested lateral pelvic lymph nodes was more in the laparoscopic group than in the open group $(19.5 v s .15 .8, P<0.05)$. In lateral pelvic lymph node dissection following neo-adjuvant chemo-radiotherapy, lymph node yield would be $\operatorname{low}^{[63]}$ and studies have shown that the number of lymph nodes does not affect the recurrence rate and survival ${ }^{[64]}$. Furuhata et al. ${ }^{[65]}$ confirmed the good oncological outcomes with perioperative morbidity of $16.7 \%$ as three patients developed grade 2 urinary retention.

Robotic surgery may facilitate lateral pelvic lymph node dissection because of its advantage over laparoscopic surgery. Initial small series have confirmed the feasibility of robotic lateral pelvic lymph node dissection ${ }^{[6,66]}$. In our institute, we standardized the technique of robotic lateral pelvic lymph node dissection ${ }^{[57]}$. We use standard five-port technique followed by completion of TME, medialization of ureter, skeletonization and dissection around external and internal iliac vessels, dissection of obliterated umbilical artery, dissection in paravesical space, standard template dissection, identification of obturator nerve, and dissection up to pelvic floor [Figure 6].

Kagawa et al. ${ }^{[68]}$ reported short-term outcomes in 50 consecutive robotic lateral pelvic lymph node dissections. The median operative time was $165 \mathrm{~min}$ (range 85-257 min) and median blood loss was $27 \mathrm{~mL}$ (range 5-690 mL). The median number of harvested lymph nodes was 19 (range 5-47). There was no conversion to open or laparoscopic approach. Clavien-Dindo classification grade III-IV complications occurred in only one patient (2.0\%).

Yamaguchi et al. ${ }^{[69]}$ compared short-term outcomes of robotic-assisted laparoscopic lateral pelvic lymph node dissection with open approach. Operative time was significantly longer in the robotic surgery $(P=0.007)$. The blood loss and perioperative complications were significantly less in the robotic group.

Kim et al.$^{[70]}$ have compared robotic lateral pelvic lymph node dissection with laparoscopic approach. There was no significant difference in operative time between the two groups (robotic vs. laparoscopic, $41.0 \pm 15.8 \mathrm{~min} v s$. 


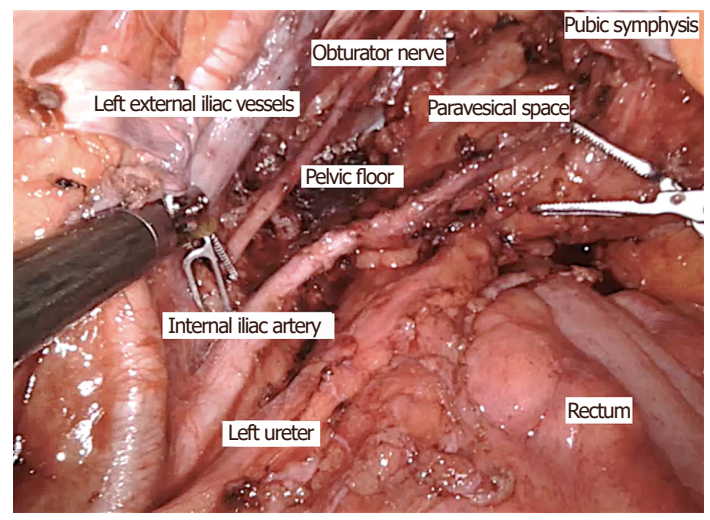

Figure 6. Robotic surgery showing template of lateral pelvic lymph node dissection

$35.3 \pm 13.4 \mathrm{~min} ; P=0.146$ ), but the estimated blood loss was significantly lower in the robotic group ( $34.6 \pm$ $21.9 \mathrm{~mL}$ vs. $50.6 \pm 23.8 \mathrm{~mL} ; P=0.002$ ). Seven patients in the laparoscopic group and two in the robotic group developed urinary retention postoperatively $(P=0.029)$. The mean number of harvested lateral pelvic lymph nodes was 6.6 (range 0-25) in the robotic group and 6.4 (range 1-14) in the laparoscopic group. Three patients $(6.0 \%)$ in the robotic group and four $(11.4 \%)$ in the laparoscopic group developed local recurrence $(P=0.653)$.

Thus, short-term outcomes of MIS for lateral pelvic lymph node dissection are acceptable and long-term oncological outcomes need to be studied further [Table 2].

\section{EXTENDED RESECTION}

Locally advanced rectal cancer adherent to adjacent organs in $10 \%-20 \%$, might be due to direct invasion or inflammation ${ }^{[68]}$. In locally recurrent rectal cancer, the plane of dissection would be very difficult due to severe fibrosis from previous surgery and adhesions between neo-rectum and adjacent organs ${ }^{[24]}$. En bloc resection of tumor along with adjacent organs is required to achieve negative margin and to prevent exposure and dissemination of tumor cells as it is difficult to determine if these adhesions are benign or malignant ${ }^{[23,33]}$. Several studies suggested that en bloc resection of prostate/seminal vesicle is an acceptable option to avoid total pelvic exenteration in selected patients ${ }^{[23,71,72]}$. The controversy still exists on options of treatment following neo-adjuvant chemo-radiotherapy in locally advanced rectal cancer with adjacent organ involvement. A recent study by Denost et al. ${ }^{[5]}$ suggested that TME or e-TME are technically and oncologically feasible and should be considered in preference to b-TME in responders. They also reported that b-TME procedures should be preferred in non-responders, allowing for high rates of morbidity and local recurrence in patients with e-TME.

In our institute, extended resections are performed in carefully selected patients by balancing oncological safety and complications such as impaired urinary and sexual functions, as most of the patients belong to younger age group ${ }^{[33]}$. However, achieving an Ro resection is the primary goal of surgery. We do perform these resections by MIS approach ${ }^{[35]}$. Seminal vesicle is the most common adjacent organ involved in male patient ${ }^{[73]}$. We standardized our technique of laparoscopic seminal vesicle excision along with TME in locally advanced rectal cancer ${ }^{[35]}$. Technique differs from standard TME in anterior plane of dissection. Anterior peritoneal dissection started higher on urinary bladder followed by identification and division of vas deferens, dissection of distal ureter, identification of seminal vesicle, and dissection anterior to seminal vesicle till Denonvilliers' fascia is cut [Figures 7 and 8]. The most important step of surgery is identification and dissection of ureter where it arches below the vas deferens mostly when the disease involves tip of seminal vesicle [Figure 9]. If the base of seminal vesicle is involved, the ureters are usually spared. 


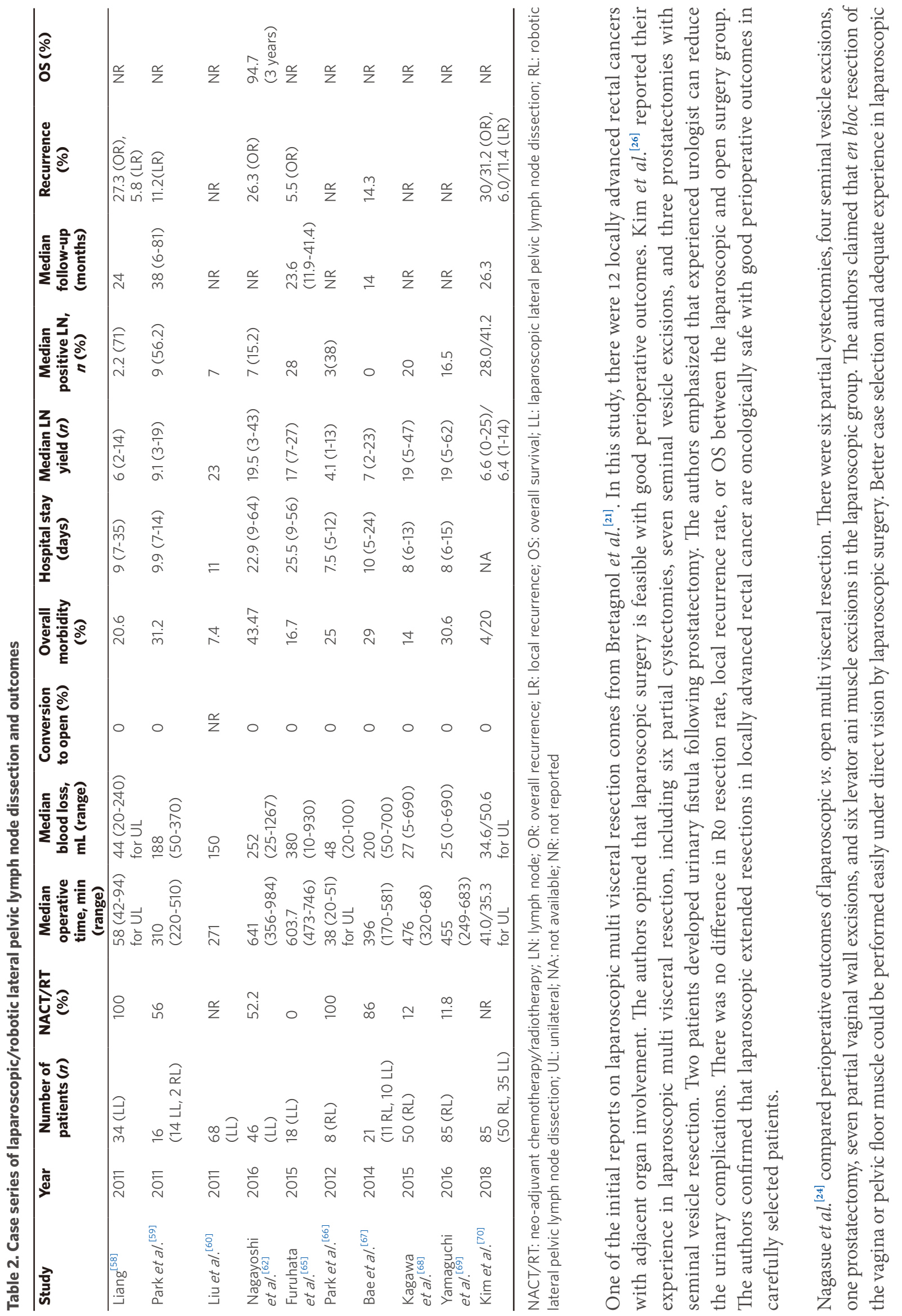




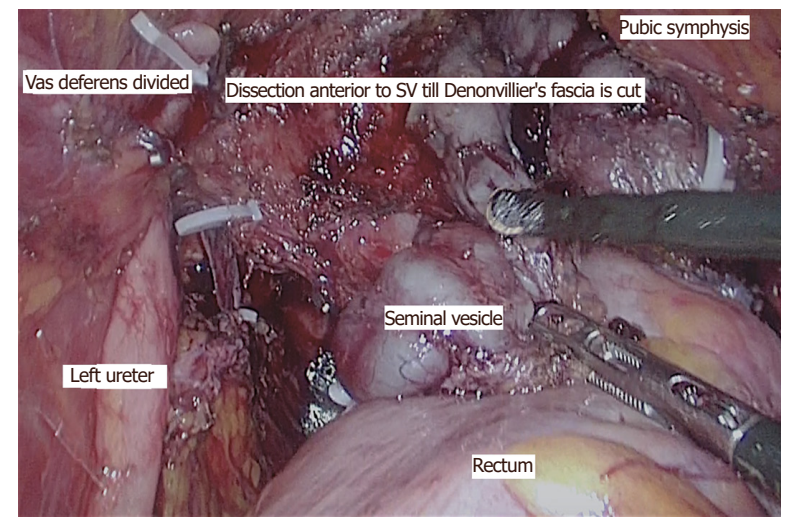

Figure 7. Laparoscopic anterior resection with seminal vesicle excision

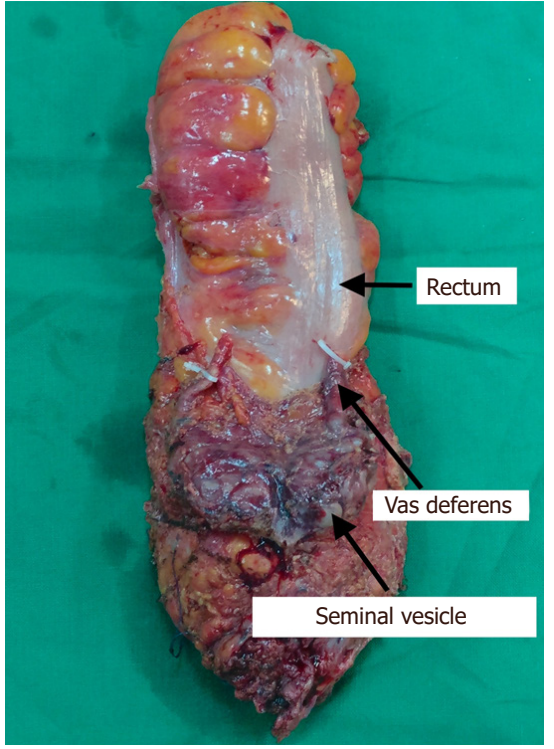

Figure 8. Specimen of laparoscopic anterior resection with seminal vesicle excision

surgery are paramount for successful laparoscopic extended resections. Nagasaki et al ${ }^{[25]}$ confirmed the role of laparoscopic extended resections for locally recurrent rectal cancer to achieve Ro resection.

The reports on robotic extended resections are scarce. One of the largest series of robotic extended resections was published by Shin et al. ${ }^{[7]}$. The study included eight prostate or seminal vesicle excisions, three partial cystectomies, and five partial vaginal wall excisions along with other multi visceral resections. There were urinary leakage in one patient and five patients developed urinary retention. Ro resection was achieved in all patients. The 5-year cumulative local recurrence rate was 3.6\%. The 5-year actuarial disease-free rate was $54.6 \%$ and an OS rate was $80 \%$. The authors confirmed that the robotic extended resection is safe and feasible with good perioperative outcomes, a low risk for conversion, a high rate of Ro resection, and acceptable longterm oncological outcomes.

\section{ABDOMINOSACRAL RESECTION}

Abdominosacral resection is required when locally advanced/recurrent rectal cancer involves presacral fascia and sacrum. Williams et al. ${ }^{[75]}$ reported an Ro resection following laparoscopic abdominosacral 


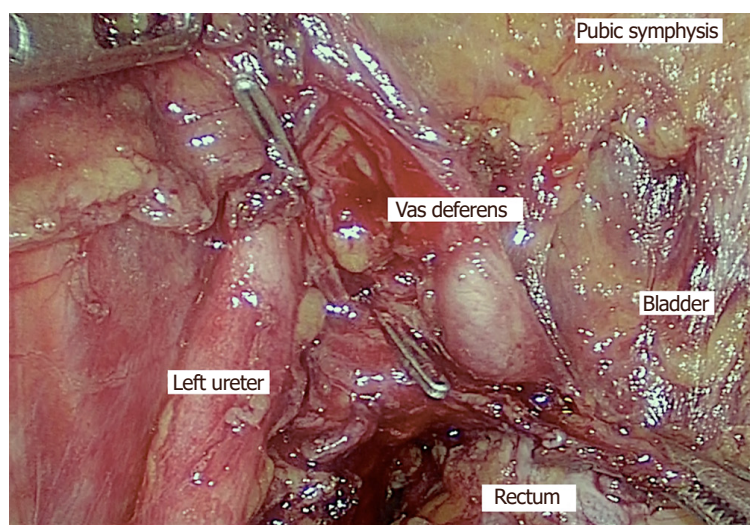

Figure 9. Laparoscopic extended resection showing distal ureter where it arches below the vas deferens

resection in three patients with locally advanced rectal cancer. After abdominal part of laparoscopic surgery, sacral resection (below S3/S4) was performed in prone position. Laparoscopic abdominosacral resection provides short-term benefits of MIS approach with negative circumferential margin ${ }^{[76,77]}$. Uemura et al. ${ }^{[78]}$ recently reported a complete laparoscopic abdominosacral resection using a Gigli wire saw for a locally recurrent rectal cancer. The distance between the estimated line of resection (below the S4 vertebra) and sacral promontory was measured by preoperative imaging. Intraoperatively, line of resection was marked and Gigli wire was passed dorsal to sacral bone at the level of resection. Both the ends of wire were brought out through lower abdominal ports and sacrum was cut by the linear reciprocating motion of the Gigli wire saw.

This review has several limitations. There were no randomized controlled trials or prospective studies available in the current literature in context to this review. There was heterogeneity between the studies with small sample size. There were no studies with long-term follow-up to evaluate oncological outcomes. Shortterm outcomes were variable due to patient selection bias and heterogeneity in the available studies.

\section{CONCLUSIONS}

The technological advances in instrumentation, advances in surgical techniques, increased surgeon experience made MIS feasible with good perioperative outcomes in b-TME/e-TME in carefully selected patients. Laparoscopic surgery has considerable learning curve and should be performed by experienced surgical teams. Robotic surgery is feasible and beneficial in complex resection in pelvis. However, evidence for long-term oncological outcomes of MIS in b-TME/e-TME is low and needs to be studied further by randomized controlled trial once enough numbers are possible in institutes with high volume rate.

\section{DECLARATIONS}

\section{Authors' contributions}

Concepts and definition of intellectual content: Kumar NAN, Saklani A

Literature search: Kumar NAN, Kammar P

Design, manuscript preparation, editing, and review: Kumar NAN, Kammar P, Saklani A

\section{Availability of data and materials}

Not applicable.

\section{Financial support and sponsorship}

None. 


\section{Conflicts of interest}

The authors declare that there are no conflicts of interest.

\section{Ethical approval and consent to participate}

Not applicable.

\section{Consent for publication}

Not applicable.

\section{Copyright}

(c) The Author(s) 2018.

\section{REFERENCES}

1. Bhangu A, Ali SM, Brown G, Nicholls RJ, Tekkis P. Indications and outcome of pelvic exenteration for locally advanced primary and recurrent rectal cancer. Ann Surg 2014;259:315-22.

2. Georgiou PA, Tekkis PP, Brown G. Pelvic colorectal recurrence: crucial role of radiologists in oncologic and surgical treatment options. Cancer Imaging 2011;11:S103-11.

3. Georgiou PA, Tekkis PP, Constantinides VA, Patel U, Goldin RD, Darzi AW, John Nicholls R, Brown G. Diagnostic accuracy and value of magnetic resonance imaging (MRI) in planning exenterative pelvic surgery for advanced colorectal cancer. Eur J Cancer 2013;49:72-81.

4. Georgiou P, Brown G, Constantinides V, Antoniou A, Nicholls R, Tekkis P. Diagnostic accuracy of MRI in assessing tumor invasion within pelvic compartments in recurrent and locally advanced rectal cancer. Dis Colon Rectum 2009;52:9.

5. Denost Q, Kontovounisios C, Rasheed S, Chevalier R, Brasio R, Capdepont M, Rullier E, Tekkis PP. Individualizing surgical treatment based on tumour response following neoadjuvant therapy in T4 primary rectal cancer. Eur J Surg Oncol 2017;43:92-9.

6. Smith JD, Nash GM, Weiser MR, Temple LK, Guillem JG, Paty PB. Multivisceral resections for rectal cancer. Br J Surg 2012;99:1137-43.

7. Beyond TME Collaborative. Consensus statement on the multidisciplinary management of patients with recurrent and primary rectal cancer beyond total mesorectal excision planes. Br J Surg 2013;100:1009-14.

8. Kim MJ, Chan Park S, Kim TH, Kim DY, Kim SY, Baek JY, Chang HJ, Park JW, Oh JH. Is lateral pelvic node dissection necessary after preoperative chemoradiotherapy for rectal cancer patients with initially suspected lateral pelvic node? Surgery 2016;160:366-76.

9. Kim MJ, Kim TH, Kim DY, Kim SY, Baek JY, Chang HJ, Park SC, Park JW, Oh JH. Can chemoradiation allow for omission of lateral pelvic node dissection for locally advanced rectal cancer? J Surg Oncol 2015;111:459-64.

10. Yang TX, Morris DL, Chua TC. Pelvic exenteration for rectal cancer: a systematic review. Dis Colon Rectum 2013;56:519-31.

11. Guillou PJ, Quirke P, Thorpe H, Walker J, Jayne DG, Smith AMH, Heath RM, Brown JM; MRC CLASICC Trial Group. Short-term endpoints of conventional versus laparoscopic-assisted surgery in patients with colorectal cancer (MRC CLASICC trial): multicentre, randomised controlled trial. Lancet 2005;365:1718-26.

12. Jeong SY, Park JW, Nam BH, Kim S, Kang SB, Lim SB, Choi HS, Kim DW, Chang HJ, Kim DY, Jung KH, Kim TY, Kang GH, Chie EK, Kim SY, Sohn DK, Kim DH, Kim JS, Lee HS, Kim JH, Oh JH. Open versus laparoscopic surgery for mid-rectal or lowrectal cancer after neoadjuvant chemoradiotherapy (COREAN trial): survival outcomes of an open-label, non-inferiority, randomised controlled trial. Lancet Oncol 2014;15:767-74.

13. van der Pas MH, Haglind E, Cuesta MA, Fürst A, Lacy AM, Hop WC, Bonjer HJ; Colorectal Cancer Laparoscopic or Open Resection II (COLOR II) Study Group. Laparoscopic versus open surgery for rectal cancer (COLOR II): short-term outcomes of a randomised, phase 3 trial. Lancet Oncol 2013;14:210-8.

14. Rodríguez-Sanjuán JC, Gómez-Ruiz M, Trugeda-Carrera S, Manuel-Palazuelos C, López-Useros A, Gómez-Fleitas M. Laparoscopic and robot-assisted laparoscopic digestive surgery: present and future directions. World J Gastroenterol 2016;22:1975-2004.

15. Park S, Kim NK. The role of robotic surgery for rectal cancer: overcoming technical challenges in laparoscopic surgery by advanced techniques. J Korean Med Sci 2015;30:837-46.

16. Lanfranco AR, Castellanos AE, Desai JP, Meyers WC. Robotic surgery: a current perspective. Ann Surg 2004;239:14-21.

17. Park EJ, Cho MS, Baek SJ, Hur H, Min BS, Baik SH, Lee KY, Kim NK. Long-term oncologic outcomes of robotic low anterior resection for rectal cancer: a comparative study with laparoscopic surgery. Ann Surg 2015;261:129-37.

18. Saklani AP, Lim DR, Hur H, Min BS, Baik SH, Lee KY, Kim NK. Robotic versus laparoscopic surgery for mid-low rectal cancer after neoadjuvant chemoradiation therapy: comparison of oncologic outcomes. Int J Colorectal Dis 2013;28:1689-98.

19. Xiong B, Ma L, Zhang C, Cheng Y. Robotic versus laparoscopic total mesorectal excision for rectal cancer: a meta-analysis. J Surg Res 2014;188:404-14.

20. Jayne D, Pigazzi A, Marshall H, Croft J, Corrigan N, Copeland J, Quirke P, West N, Rautio T, Thomassen N, Tilney H, Gudgeon M, Bianchi PP, Edlin R, Hulme C, Brown J. Effect of robotic-assisted vs conventional laparoscopic surgery on risk of conversion to open laparotomy among patients undergoing resection for rectal cancer: the ROLARR randomized clinical trial. JAMA 2017;318:1569-80. 
21. Bretagnol F, Dedieu A, Zappa M, Guedj N, Ferron M, Panis Y. T4 colorectal cancer: is laparoscopic resection contraindicated? Colorectal Dis 2011;13:138-43.

22. de'Angelis N, Landi F, Vitali GC, Memeo R, Martínez-Pérez A, Solis A, Assalino M, Vallribera F, Mercoli HA, Marescaux J, Mutter D, Ris F, Espin E, Brunetti F. Multicentre propensity score-matched analysis of laparoscopic versus open surgery for T4 rectal cancer. Surg Endosc 2017;31:3106-21.

23. Park SY, Choi G-S, Jun SH, Park J-S, Kim HJ. Laparoscopic salvage surgery for recurrent and metachronous colorectal cancer: 15 years' experience in a single center. Surg Endosc 2011;25:3551-8.

24. Nagasue Y, Akiyoshi T, Ueno M, Fukunaga Y, Nagayama S, Fujimoto Y, Konishi T, Nagasaki T, Nagata J, Mukai T, Ikeda A, Ono R, Yamaguchi T. Laparoscopic versus open multivisceral resection for primary colorectal cancer: comparison of perioperative outcomes. J Gastrointest Surg 2013;17:1299-305.

25. Nagasaki T, Akiyoshi T, Ueno M, Fukunaga Y, Nagayama S, Fujimoto Y, Konishi T, Yamaguchi T. Laparoscopic salvage surgery for locally recurrent rectal cancer. J Gastrointest Surg 2014;18:1319-26.

26. Kim KY, Hwang DW, Park YK, Lee HS. A single surgeon's experience with 54 consecutive cases of multivisceral resection for locally advanced primary colorectal cancer: can the laparoscopic approach be performed safely? Surg Endosc 2012;26:493-500.

27. Sasson AR, Sigurdson ER. Management of locally advanced rectal cancer. Surg Oncol 2000;9:193-204.

28. Mukai T, Akiyoshi T, Ueno M, Fukunaga Y, Nagayama S, Fujimoto Y, Konishi T, Ikeda A, Yamaguchi T. Laparoscopic total pelvic exenteration with en bloc lateral lymph node dissection after neoadjuvant chemoradiotherapy for advanced primary rectal cancer. Asian J Endosc Surg 2013;6:314-7.

29. Uehara K, Nakamura H, Yoshino Y, Arimoto A, Kato T, Yokoyama Y, Ebata T, Nagino M. Initial experience of laparoscopic pelvic exenteration and comparison with conventional open surgery. Surg Endosc 2016;30:132-8.

30. Patel H, Joseph JV, Amodeo A, Kothari K. Laparoscopic salvage total pelvic exenteration: is it possible post-chemo-radiotherapy? J Minim Access Surg 2009;5:111-4.

31. Akiyoshi T, Nagasaki T, Ueno M. Laparoscopic total pelvic exenteration for locally recurrent rectal cancer. Ann Surg Oncol 2015;22:3896.

32. Ogura A, Akiyoshi T, Konishi T, Fujimoto Y, Nagayama S, Fukunaga Y, Ueno M. Safety of laparoscopic pelvic exenteration with urinary diversion for colorectal malignancies. World J Surg 2016;40:1236-43.

33. Patil PS, Saklani A, Gambhire P, Mehta S, Engineer R, De'Souza A, Chopra S, Bal M. Colorectal cancer in India: an audit from a tertiary center in a low prevalence area. Indian J Surg Oncol 2017;8:484-90.

34. Pai VD, Jatal S, Ostwal V, Engineer R, Arya S, Patil P, Bal M, Saklani AP. Multivisceral resections for rectal cancers: short-term oncological and clinical outcomes from a tertiary-care center in India. J Gastrointest Oncol 2016;7:345-53.

35. Sinukumar S, Engineer R, Saklani A. Preliminary experience with lateral pelvic lymph node dissection in locally advanced rectal cancer. Indian J Gastroenterol 2015;34:320-4.

36. Pai VD, Bhandare M, Saklani AP. Laparoscopic total mesorectal excision with enbloc resection of seminal vesicle for locally advanced rectal adenocarcinoma. J Laparoendosc Adv Surg Tech A 2016;26:209-12.

37. Bhamre R, Pokharkar A, Shinde R, Saklani A. Laparoscopic total pelvic exenteration for locally advanced carcinoma of the rectum - a video vignette. Colorectal Dis 2018;20:161-2.

38. Pokharkar A, Kammar P, D'souza A, Bhamre R, Sugoor P, Saklani A. Laparoscopic pelvic exenteration for locally advanced rectal cancer, technique and short-term outcomes. J Laparoendosc Adv Surg Tech A 2018; doi: 10.1089/lap.2018.0147.

39. Hayashi K, Kotake M, Kakiuchi D, Yamada S, Hada M, Kato Y, Hiranuma C, Oyama K, Hara T. Laparoscopic total pelvic exenteration using transanal minimal invasive surgery technique with en bloc bilateral lymph node dissection for advanced rectal cancer. Surg Case Rep 2016;2:74.

40. Uematsu D, Akiyama G, Sugihara T, Magishi A, Yamaguchi T, Sano T. Transanal total pelvic exenteration: pushing the limits of transanal total mesorectal excision with transanal pelvic exenteration. Dis Colon Rectum 2017;60:647-8.

41. Vasilescu C, Tudor S, Popa M, Aldea B, Gluck G. Entirely robotic total pelvic exenteration. Surg Laparosc Endosc Percutan Tech 2011;21:e200-2.

42. Castillo OA, Vidal-Mora I, Rodriguez-Carlin A, Silva A, Schatloff O. First report: robot-assisted total pelvic exenteration for locally advanced prostate cancer. J Laparoendosc Adv Surg Tech A 2015;25:592-4.

43. Nanayakkara PR, Ahmed SA, Oudit D, O’Dwyer ST, Selvasekar CR. Robotic assisted minimally invasive pelvic exenteration in advanced rectal cancer: review and case report. J Robot Surg 2014;8:173-5.

44. Shin JW, Kim J, Kwak JM, Hara M, Cheon J, Kang SH, Kang SG, Stevenson AR, Coughlin G, Kim SH. First report: robotic pelvic exenteration for locally advanced rectal cancer. Colorectal Dis 2014;16:O9-14.

45. Winters BR, Mann GN, Louie O, Wright JL. Robotic total pelvic exenteration with laparoscopic rectus flap: initial experience. Case Rep Surg 2015;2015:835425.

46. Malakorn S, Sammour T, Pisters LL, Chang GJ. Robotic total pelvic exenteration. Dis Colon Rectum 2017;60:555.

47. Kim TH, Jeong SY, Choi DH, Kim DY, Jung KH, Moon SH, Chang HJ, Lim SB, Choi HS, Park JG. Lateral lymph node metastasis is a major cause of locoregional recurrence in rectal cancer treated with preoperative chemoradiotherapy and curative resection. Ann Surg Oncol 2008;15:729-37.

48. Yano H, Moran BJ. The incidence of lateral pelvic side-wall nodal involvement in low rectal cancer may be similar in Japan and the West. Br J Surg 2008;95:33-49. 
49. Akiyoshi T, Watanabe T, Miyata S, Kotake K, Muto T, Sugihara K; Japanese Society for Cancer of the Colon and Rectum. Results of a Japanese nationwide multi-institutional study on lateral pelvic lymph node metastasis in low rectal cancer: is it regional or distant disease? Ann Surg 2012;255:1129-34.

50. Watanabe T, Itabashi M, Shimada Y, Tanaka S, Ito Y, Ajioka Y, Hamaguchi T, Hyodo I, Igarashi M, Ishida H, Ishihara S, Ishiguro M, Kanemitsu Y, Kokudo N, Muro K, Ochiai A, Oguchi M, Ohkura Y, Saito Y, Sakai Y, Ueno H, Yoshino T, Boku N, Fujimori T, Koinuma N, Morita T, Nishimura G, Sakata Y, Takahashi K, Tsuruta O. Japanese Society for Cancer of the Colon and Rectum (JSCCR) Guidelines 2014 for treatment of colorectal cancer. Int J Clin Oncol 2015;20:207-39.

51. Moran B. Exploring the limits in low rectal cancer. Lancet Oncol 2012;13:565-7.

52. Akiyoshi T, Ueno M, Matsueda K, Konishi T, Fujimoto Y, Nagayama S, Fukunaga Y, Unno T, Kano A, Kuroyanagi H, Oya M, Yamaguchi T, Watanabe T, Muto T. Selective lateral pelvic lymph node dissection in patients with advanced low rectal cancer treated with preoperative chemoradiotherapy based on pretreatment imaging. Ann Surg Oncol 2014;21:189-96.

53. Nagawa H, Muto T, Sunouchi K, Higuchi Y, Tsurita G, Watanabe T, Sawada T. Randomized, controlled trial of lateral node dissection vs. nerve-preserving resection in patients with rectal cancer after preoperative radiotherapy. Dis Colon Rectum 2001;44:1274-80.

54. Fujita S, Akasu T, Mizusawa J, Saito N, Kinugasa Y, Kanemitsu Y, Ohue M, Fujii S, Shiozawa M, Yamaguchi T, Moriya Y; Colorectal Cancer Study Group of Japan Clinical Oncology Group. Postoperative morbidity and mortality after mesorectal excision with and without lateral lymph node dissection for clinical stage II or stage III lower rectal cancer (JCOG0212): results from a multicentre, randomised controlled, non-inferiority trial. Lancet Oncol 2012;13:616-21.

55. Gk K, Vd P, Ap S. Is there a role of lateral pelvic lymph node dissection in the current era of neoadjuvant chemoradiotherapy for rectal cancer? J Gastrointest Digest Syst 2016;6:1-4.

56. Mahendra BK, Vallam KC, Saklani A. Lateral pelvic lymph node dissection - are we ready to bridge the gap between the west and the east? Ann Laparosc Endosc Surg 2017;2:158.

57. Sasi S, Rohila J, Kammar P, Kurunkar S, Desouza A, Saklani A. Robotic lateral pelvic lymph node dissection (LPLND) in rectal cancer - video vignette. Colorectal Dis 2018;20:554-5.

58. Liang JT. Technical feasibility of laparoscopic lateral pelvic lymph node dissection for patients with low rectal cancer after concurrent chemoradiation therapy. Ann Surg Oncol 2011;18:153-9.

59. Park JS, Choi GS, Lim KH, Jang YS, Kim HJ, Park SY, Jun SH. Laparoscopic extended lateral pelvic node dissection following total mesorectal excision for advanced rectal cancer: initial clinical experience. Surg Endosc 2011;25:3322-9.

60. Liu T, Zhang C, Yu P, Chen J, Zeng D, Gan L, Lv W, Liu L, Yan X. Laparoscopic radical correction combined with extensive lymphadenectomy and pelvic autonomic nerve preservation for mid-to-low rectal cancer. Clin Colorectal Cancer 2011;10:183-7.

61. Akiyoshi T. Technical feasibility of laparoscopic extended surgery beyond total mesorectal excision for primary or recurrent rectal cancer. World J Gastroenterol 2016;22:718-26.

62. Nagayoshi K, Ueki T, Manabe T, Moriyama T, Yanai K, Oda Y, Tanaka M. Laparoscopic lateral pelvic lymph node dissection is achievable and offers advantages as a minimally invasive surgery over the open approach. Surg Endosc 2016;30:1938-47.

63. Wichmann MW, Müller C, Meyer G, Strauss T, Hornung HM, Lau-Werner U, Angele MK, Schildberg FW. Effect of preoperative radiochemotherapy on lymph node retrieval after resection of rectal cancer. Arch Surg 2002;137:206-10.

64. Kim YW, Kim NK, Min BS, Lee KY, Sohn SK, Cho CH, Kim H, Keum KC, Ahn JB. The prognostic impact of the number of lymph nodes retrieved after neoadjuvant chemoradiotherapy with mesorectal excision for rectal cancer. J Surg Oncol 2009;100:1-7.

65. Furuhata T, Okita K, Nishidate T, Ito T, Yamaguchi H, Ueki T, Akizuki E, Meguro M, Ogawa T, Kukita K, Kimura Y, Mizuguchi T, Hirata K. Clinical feasibility of laparoscopic lateral pelvic lymph node dissection following total mesorectal excision for advanced rectal cancer. Surg Today 2015;45:310-4.

66. Park JA, Choi GS, Park JS, Park SY. Initial clinical experience with robotic lateral pelvic lymph node dissection for advanced rectal cancer. J Korean Soc Coloproctol 2012;28:265-70.

67. Bae SU, Saklani AP, Hur H, Min BS, Baik SH, Lee KY, Kim NK. Robotic and laparoscopic pelvic lymph node dissection for rectal cancer: short-term outcomes of 21 consecutive series. Ann Surg Treat Res 2014;86:76-82.

68. Kagawa H, Kinugasa Y, Shiomi A, Yamaguchi T, Tsukamoto S, Tomioka H, Yamakawa Y, Sato S. Robotic-assisted lateral lymph node dissection for lower rectal cancer: short-term outcomes in 50 consecutive patients. Surg Endosc 2015;29:995-1000.

69. Yamaguchi T, Kinugasa Y, Shiomi A, Tomioka H, Kagawa H. Robotic-assisted laparoscopic versus open lateral lymph node dissection for advanced lower rectal cancer. Surg Endosc 2016;30:721-8.

70. Kim HJ, Choi GS, Park JS, Park SY, Lee HJ, Woo IT, Park IK. Selective lateral pelvic lymph node dissection: a comparative study of the robotic versus laparoscopic approach. Surg Endosc 2018;32:2466-73.

71. Wiig JN, Waehre H, Larsen SG, Braendengen M, Giercksky KE. Radical prostatectomy for locally advanced primary or recurrent rectal cancer. Eur J Surg Oncol 2003;29:455-8.

72. Saito N, Suzuki T, Sugito M, Ito M, Kobayashi A, Tanaka T, Kotaka M, Karaki H, Kobatake T, Tsunoda Y, Shiomi A, Yano M, Minagawa N, Nishizawa Y. Bladder-sparing extended resection of locally advanced rectal cancer involving the prostate and seminal vesicles. Surg Today 2007;37:845-52.

73. Smith JD, Nash GM, Weiser MR, Temple LK, Guillem JG, Paty PB. Multivisceral resections for rectal cancer. Br J Surg 2012;99:1137-43.

74. Shin US, You YN, Nguyen AT, Bednarski BK, Messick C, Maru DM, Dean EM, Nguyen ST, Hu CY, Chang GJ. Oncologic outcomes of extended robotic resection for rectal cancer. Ann Surg Oncol 2016;23:2249-57.

75. Williams GL, Gonsalves S, Bandyopadhyay D, Sagar PM. Laparoscopic abdominosacral composite resection for locally advanced 
primary rectal cancer. Tech Coloproctol 2008;12:299-302.

76. Nagasaki T, Akiyoshi T, Ueno M, Fukunaga Y, Nagayama S, Fujimoto Y, Konishi T, Yamaguchi T. Laparoscopic abdominosacral resection for locally advanced primary rectal cancer after treatment with mFOLFOX6 plus bevacizumab, followed by preoperative chemoradiotherapy. Asian J Endosc Surg 2014;7:52-5.

77. Lengyel J, Sagar PM, Morrison C, Gonsalves S, Lee P, Phillips N. Multimedia article. Laparoscopic abdominosacral composite resection. Dis Colon Rectum 2009;52:1662-4.

78. Uemura M, Ikeda M, Kawai K, Nishimura J, Takemasa I, Mizushima T, Yamamoto H, Sekimoto M, Doki Y, Mori M. Laparoscopic surgery using a Gigli wire saw for locally recurrent rectal cancer with concomitant intraperitoneal sacrectomy. Asian J Endosc Surg 2018;11:83-6. 